\title{
Levodopa Challenge Neuroimaging of Levodopa-Related Mood Fluctuations in Parkinson's Disease
}

\author{
Kevin J Black*, 1,2,3,4, Tamara Hershey ${ }^{1,2,4}$, Johanna M Hartlein ${ }^{1,4}$, Juanita $L$ Carl ${ }^{2,4}$ and \\ Joel S Perlmutter ${ }^{1,2,4,5,6}$
}

'Department of Psychiatry, Washington University School of Medicine, St Louis, MO, USA; ${ }^{2}$ Department of Neurology and Neurosurgery, Washington University School of Medicine, St Louis, MO, USA; ${ }^{3}$ Department of Radiology and Mallinckrodt Institute of Radiology, Washington University School of Medicine, St Louis, MO, USA; ${ }^{4}$ APDA Advanced Research Center for Parkinson Disease, Washington University School of Medicine, St Louis, MO, USA; ${ }^{5}$ Department of Anatomy and Neurobiology, Washington University School of Medicine, St Louis, MO, USA;

${ }^{6}$ Program in Physical Therapy, Washington University School of Medicine, St Louis, MO, USA

Some patients with advanced Parkinson's disease (PD) develop dose-related fluctuations in mood. This may reflect alterations in dopamine-influenced brain circuits that mediate emotion. However, there is no available information to localize which dopamineinfluenced neurons may be most affected. Eight patients with PD and clinically significant levodopa-related mood fluctuations (mania, depression, or anxiety) were compared to 13 patients with similarly severe PD and fluctuations of motor function but not of mood Regional cerebral blood flow (rCBF) was measured with positron emission tomography before and after levodopa (in the presence of carbidopa). The rCBF response to levodopa in medial frontal gyrus and posterior cingulate cortex (PCC) significantly differed between mood fluctuators and control patients (corrected $p<0.02$ ). Other regions with uncorrected $p<0.001$ in this comparison were cortical Brodmann areas 22, 40, I3, II, and 28, hippocampus, and claustrum. The levodopa activation paradigm detected group differences not evident in a comparison of resting rCBF. Abnormalities of dopamine innervation may produce mood fluctuations via effects on PCC, an area strongly linked to mood and anxiety and with known rCBF responsiveness to levodopa or D2-like dopamine receptor agonists. We speculate that mood fluctuations may arise in parkinsonian patients who have abnormal dopaminergic modulation of caudate nucleus, anterior cingulate cortex, or orbital frontal cortex, all of which innervate PCC. The findings require confirmation in larger and bettermatched groups.

Neuropsychopharmacology (2005) 30, 590-60I, advance online publication, I5 December 2004; doi:I 0. I038/sj.npp. I 300632

Keywords: levodopa; positron emission tomography; mood disorders; Parkinson's disease; cerebral blood flow; cingulate gyrus

\section{INTRODUCTION}

'I find my 'offs' are accompanied by a curiously deep and malevolent depression.'

from a patient with Parkinson's disease (Lees, 1989)

Mood and anxiety disorders comprise major public health problems. When mood symptoms arise in relation to specific anatomic or pharmacologic insults, this relationship may lead to knowledge of how mood symptoms are produced. One such experiment of nature occurs in some patients with advanced Parkinson's disease (PD).

\footnotetext{
*Correspondence: Dr KJ Black, Department of Psychiatry, Washington University School of Medicine, Campus Box 8134, 660 S Euclid Ave. St Louis, MO 63I I0-1093, USA, Tel: + I 314362 628I, Fax: + I 314 3620168, E-mail: kevin@wustl.edu

Received 20 February 2004; revised 28 September 2004; accepted 26 October 2004

Online publication: 2 November 2004 at http://www.acnp.org/citations/ npp | | 0204040079/default.pdf
}

Loss of dopamine-producing cells in the midbrain produces the symptoms of PD (Hornykiewicz, 1963). Levodopa ( $\mathrm{L}$-dihydroxyphenylalanine, $\mathrm{L}-\mathrm{DOPA}$ ) is a natural precursor of dopamine that crosses the blood-brain barrier and is widely used to treat PD. Early in the disease course, levodopa commonly produces dramatic and sustained symptomatic relief (Cotzias et al, 1967). However, later in the course of the illness, the benefit from a dose of levodopa may wane soon after it appears; this is referred to as 'endof-dose deterioration' or 'wearing off.' Commonly patients and physicians refer to 'on' periods, when the medication is providing motor benefit, and 'off periods, when the parkinsonian symptoms return. Interestingly, this nomenclature derives from a patient 'who likened the glow of the levodopa awakening to the switching on of a light and the equally abrupt return of parkinsonian darkness to the light going off (Lees, 1989; Duvoisin, 1974).

As this poetic description suggests, the motor fluctuations that define the on and off states are often accompanied by fluctuations of nonmotor CNS symptoms, including pain, autonomic dysfunction, cognitive problems, or emotional 
changes. Some sadness with increased disability is not surprising, and mild mood fluctuations occur in almost all PD patients with motor fluctuations (Nissenbaum et al, 1987; Hardie et al, 1984; Menza et al, 1990; Maricle et al, $1995 \mathrm{a}, \mathrm{b})$. These fluctuations are not always tightly correlated to levodopa dosing (Menza et al, 1990; Richard et al, 2001). However, a minority of patients develop severe depression, anxiety, or mania, usually with a more predictable relationship to levodopa dosing (Damásio et al, 1971; Hardie et al, 1984; Keshavan et al, 1986; Nissenbaum et al, 1987; Lees, 1989; Friedenberg and Cummings, 1989; Menza et al, 1990; Goodwin, 1990; Riley and Lang, 1993; Vázquez et al, 1993; Siemers et al, 1993; Maricle et al, $1995 \mathrm{a}, \mathrm{b})$. The focus of this report is on these more clinically significant symptoms, usually called 'mood fluctuations' in the PD literature.

These symptoms are no mere academic curiosity. Patients consider mood symptoms more disabling than their motor deficits, and caregivers consider them more stressful (Witjas et al, 2002; Carter et al, 2002). Patients with clinically significant mood fluctuations tend to have severe $\mathrm{PD}$, with early onset, long duration of illness, and extremely high rates of psychiatric comorbidity including dementia, prior (nonfluctuating) depression, and drug-induced psychosis (Racette et al, 2002).

There is some evidence that fluctuations of mood or anxiety in PD result from a direct effect of levodopa on selected brain pathways rather than a secondary psychological response to fluctuating disability. Supporting this view, mood response to a dose of levodopa precedes the improvement in motor function (Maricle et al, 1995a). Under blind conditions, a placebo causes no similar mood effect (Maricle et al, 1995b). The extent of mood change does not correlate tightly with the extent of motor improvement or with baseline severity of motor signs (Maricle et al, 1995a, 1998; Witjas et al, 2002). Finally, patients with rheumatoid arthritis and similar fluctuations in motor disability have significantly less severe fluctuations of mood (Cantello et al, 1986).

These observations suggest that PD patients with levodopa-related emotional fluctuations may have dysfunction of dopaminergic afferents to brain regions that mediate emotional responses. Unfortunately, existing data are insufficient to clarify the pharmacology or functional neuroanatomy of this fascinating dopamine-related mood syndrome.

We used an extensively validated pharmacologic challenge neuroimaging technique to identify brain structures that may be involved in the experience or provocation of emotion. Specifically, we compared regional cerebral blood flow (rCBF) responses to levodopa in PD patients with clinically significant mood fluctuations to responses in patients with similarly severe PD and motor fluctuations but no mood fluctuations. Regional CBF responses to levodopa challenge are well characterized in normal and parkinsonian humans and in other primates (Hershey et al, 1998, 2000, 2003). Pretreatment with carbidopa blocks dopamine production outside the brain and consequently prevents indiscriminate vascular effects (Hershey et al, 1998, 2000, 2003; Black et al, 2003). We hypothesized that mood fluctuators would show regional abnormalities in the rCBF response to levodopa, compared to similarly ill PD controls, reflecting altered dopamine-mediated neuronal function in specific neuroanatomical circuits that affect emotion.

\section{METHODS}

\section{Clinical Methods}

The Radioactive Drug Research Committee and the Human Studies Committee of Washington University School of Medicine (WUSM) approved this research, and all participants gave informed consent to participation. Over a 5-year period, patients with clinically diagnosed idiopathic PD were recruited from the WUSM Movement Disorders Center and through the American Parkinson Disease Association. All subjects underwent extensive psychiatric and neurological evaluation by a movement disorders specialist who is board certified in psychiatry and geriatric psychiatry. In addition, symptom severity at baseline was rated using the Mini-Mental Status Exam, Hamilton Depression Rating Scale, Hamilton Anxiety Scale, Bech mania scale, Unified Parkinson Disease Rating Scale (UPDRS), and Barnes akathisia scale.

These scales are neither practical nor most appropriate for repeated ratings of symptom severity while the patient was in the positron emission tomography (PET) scanner. Instead, patients rated various symptoms using the visual analog scale (VAS) (Folstein and Luria, 1973). The VAS ratings were recorded on $100 \mathrm{~mm}$ anchored scales and included sad-happy, akathisia, calm-anxious, pain, tremor, 'slowness and stiffness,' dystonia, dyskinesias, disabilityindependence, and apathy-motivation. All patients practiced the VAS ratings prior to the first scan and definitions were clarified with each scan using written guidelines and appropriate follow-up.

All 21 subjects had motor fluctuations as defined by a history of marked fluctuations in motor symptoms in response to individual doses of $\mathrm{PD}$ medications, in spite of appropriate pharmacological adjustments. There is no accepted convention for diagnosis of mood fluctuations. We used the criteria listed in Appendix A1 to diagnose 'clinically significant levodopa-related mood fluctuations' in eight patients and to exclude this diagnosis in 13 patients ('motor fluctuator controls'). Dose-related depressive, anxious, or manic symptoms were all included in the mood fluctuation group, since most such patients have both depressive and anxious symptoms when off, and some have on-period mania and off-period anxiety (Racette et al, 2002). Appendix A1 also contains dialogue from a representative screening interview in one patient.

All patients were excluded for other neurological illness, other psychiatric illness (except remitted major depression), or concurrent systemic illness likely to affect the CNS or make study participation unsafe. Demographic and diagnostic information is provided in Table 1 .

\section{Protocol}

Patients abstained from food and antiparkinsonian medication for at least $8 \mathrm{~h}$ prior to the study. (A longer interruption in treatment was not feasible given the marked severity of motor disability when 'off in several patients.) They took $200 \mathrm{mg}$ carbidopa by mouth and baseline ratings of severity 
Table I Demographic and Illness Information

\begin{tabular}{|c|c|c|}
\hline & $\begin{array}{c}\text { Mood } \\
\text { fluctuators }\end{array}$ & $\begin{array}{l}\text { Motor } \\
\text { fluctuator } \\
\text { controls }\end{array}$ \\
\hline Number & $8^{\mathrm{a}}$ & 13 \\
\hline Age & $59 \pm 10$ & $61 \pm 8$ \\
\hline $\operatorname{Sex}(F)$ & 6 & 5 \\
\hline Handedness $(\mathrm{RH})$ & 7 & 10 \\
\hline Years PD & $12 \pm 6$ & $10 \pm 3$ \\
\hline Severity $(H \& Y)^{b}$ & $2.2 \pm 0.3$ & $2.5 \pm 0.7$ \\
\hline Worst side $(R>L)$ & 2 & 3 \\
\hline Antidepressant $^{c}$ & 6 & 5 \\
\hline Usual daily antiparkinsonian dose $(\mathrm{mg})^{\mathrm{d}}$ & $1217 \pm 380$ & $862 \pm 338 *$ \\
\hline \multicolumn{3}{|c|}{$\begin{array}{l}\text { aSee Table } 5 \text { for specific mood fluctuation types. } \\
\text { bH\&Y: Hoehn and Yahr scale. } \\
\text { 'Currently taking an antidepressant at any dose. In mood fluctuators these were } \\
\text { sertraline in three subjects ( } 25,150 \text {, and } 150 \mathrm{mg} / \text { day); mirtazapine in two } \\
\text { subjects ( } 15 \text { and } 60 \mathrm{mg} / \text { day); amitriptyline in one subject ( } 25 \mathrm{mg} / \mathrm{day}) \text {. Each of } \\
\text { the following regimens was used by one motor fluctuator control: venlafaxine } \\
\text { ( } 225 \mathrm{mg} / \text { day) and trazodone ( } 50 \mathrm{mg} / \text { day); paroxetine }(20 \mathrm{mg} / \mathrm{day}) \text { and } \\
\text { imipramine ( } 50 \mathrm{mg} / \text { day); sertraline } 100 \mathrm{mg} / \text { day; trazodone ( } 175 \mathrm{mg} / \mathrm{day}) \text {; } \\
\text { amitriptyline ( } 50 \mathrm{mg} / \text { day). } \\
\text { dEquivalent dose of levodopa or dopamine agonists using the method of } \\
\text { Hobson et al (2002). Other medications included amantadine (one mood, three } \\
\text { motor), selegiline (zero mood, two motor), and benztropine (zero mood, one } \\
\text { motor). } \\
\text { * } p<0.05 \text {, uncorrected for multiple comparisons (all other table rows } p>0.10 \text { ) }\end{array}$} \\
\hline
\end{tabular}

were recorded. Subjects then were placed in the scanner with an individually molded polyform mask to help minimize head movement. A 20-gauge catheter was inserted into an antecubital vein to permit injection of $\mathrm{H}_{2}^{15} \mathrm{O}$.

We performed three baseline PET measurements of $\mathrm{rCBF}$ at least $10 \mathrm{~min}$ apart. We then administered levodopa and repeated three PET rCBF scans. During each PET scan, the room was darkened and quiet, and subjects remained still with eyes closed. Just before or after each scan (when possible), patients recorded VAS symptom ratings and we performed modified UPDRS ratings. We selected items from motor subscale 3 from UPDRS that could be assessed with the patient in the scanner, including tremor, rigidity, and bradykinesia for upper extremities (16 total possible points for each side, 32 points total) (Hershey et al, 1998). Initially, levodopa was administered orally as $150 \mathrm{mg}$ levodopa/37.5 mg carbidopa, but after difficulties with variable absorption in some patients in a parallel study we abandoned this in favor of an approximately bioequivalent dose given by the intravenous (i.v.) route (the intermediatedose protocol in Black et al, 2003). By way of comparison, the average usual morning dose of antiparkinsonian medication in these patients was equivalent to about $250 \mathrm{mg}$ levodopa using the formula of Hobson et al (2002), with no group difference ( $t$-test, $p>0.30$ ). Seven subjects in each group received levodopa i.v. The onlevodopa scans were performed at $\sim 45-75 \mathrm{~min}$ after oral levodopa or $\sim 30-60 \mathrm{~min}$ after the start of the i.v. infusion; these times were chosen a priori to match the expected time of peak blood levels (for oral dosing) and to approximate these same blood levels (for i.v. dosing).

\section{Levodopa/Carbidopa Quantification}

In patients who received oral levodopa, blood samples for determination of plasma levodopa concentration were taken through the i.v. catheter. In patients who received i.v. levodopa, the sampling was performed through a second 20gauge catheter placed in a vein in the contralateral upper extremity. Samples were taken before administration of levodopa and again just after each post-levodopa PET scan. Concentrations were measured using high-performance liquid chromatography with electrochemical detection (Baruzzi et al, 1986; Carl and Perlmutter, 1998).

\section{PET Methods}

PET studies were performed in 2D mode on a Siemens 953B or 961 HR scanner (CTI, Knoxville, TN). Only one subject in each patient group was studied on the 953B scanner. On the 953B scanner, data were recorded simultaneously for 31 slices with a center-to-center slice separation of $3.4 \mathrm{~mm}$. On the 961 scanner, data were recorded simultaneously for 47 slices with a $3.25 \mathrm{~mm}$ center-to-center slice separation. After subjects were positioned, a transmission scan used for individual attenuation correction was acquired with rotating rod sources containing ${ }^{68} \mathrm{Ge} /{ }^{68} \mathrm{Ga}$. Blood flow was measured using a 40 -s emission scan following the i.v. bolus injection of $5-10 \mathrm{ml}$ of saline containing $40-50 \mathrm{mCi}$ of ${ }^{15} \mathrm{O}$ labeled water (Raichle et al, 1983; Herscovitch et al, 1983; Videen et al, 1987).

\section{Image Processing}

Data from both scanners were combined, given the similar image resolution and the limited number of available subjects. Images were aligned within subject and nonlinearly transformed to match the MNI instantiation of Talairach and Tournoux atlas space, using the methods in the SPM99 software package (http://www.fil.ion.ucl.ac.uk/ spm/spm99.html) (Talairach and Tournoux, 1988; Mazziotta et al, 1995; Friston et al, 1995). The atlas-transformed images were spatially filtered with an $18 \mathrm{~mm}$ (FWHM) Gaussian filter and intensity normalized.

\section{Statistical Analysis}

Clinical features were compared using a two-tailed $t$-test for quantitative data and the $\chi^{2}$-test for categorical data. Changes with levodopa were tested using repeated measures ANOVA.

Only voxels present in all atlas-transformed images were further analyzed. (The most superior part of cortex was not covered in the two 953b subjects.) Using SPM99, a general linear model was computed at each voxel with variables coding for diagnosis (mood fluctuations $v s$ motor fluctuations only), drug status (baseline $v s$ on-levodopa), and individual (a Boolean variable for each subject). The primary contrast compared response to levodopa between the two patient groups. Fixed effects analysis was performed given the small numbers of subjects in each group. Secondary analyses were (1) a between-group comparison of baseline rCBF and (2) the response to levodopa across all subjects. Using SPM99, the statistical significance was 
corrected for multiple comparisons based on the size of each cluster of contiguous voxels having $t>3.17$, corresponding to $p=0.001$ uncorrected $(\mathrm{df}=100)$. The a priori decision was to consider significant only clusters with a corrected $p<0.05$. However, this is a conservative choice and may not detect all meaningful responses. Therefore, we also report all other intracerebral clusters defined by voxelwise $p<0.001$. We also report an experimentwise (also called 'omnibus' or 'set-level') statistic reflecting the likelihood, computed by SPM99, of obtaining by chance the observed number of suprathreshold clusters.

Relative CBF in regions identified by the statistical analysis was further examined as follows. Spherical volumes of interest (VOIs) with diameter $8 \mathrm{~mm}$ were centered on local maxima at least $8 \mathrm{~mm}$ apart ('peaks'), and average voxel values from each VOI were obtained from each atlas-transformed, smoothed $\mathrm{rCBF}$ image and expressed as the ratio to the average voxel value in all analyzed voxels.

\section{RESULTS}

\section{PET: Comparison of Baseline rCBF between Mood Fluctuators and Controls}

There were no statistically significant responses at corrected $p<0.05$. At an uncorrected threshold corresponding to $p<0.001$, one small cluster of voxels, with local maximum (peak) at $(-2,-54,20)$, showed lower baseline rCBF in the mood fluctuator group (peak $t=3.76,19 \mathrm{df}, 0.2 \mathrm{ml}$ ). This peak lies in the posterior cingulate cortex (PCC) (Brodmann area (BA) 23) near retrosplenial cortex, $32 \mathrm{~mm}$ posterior and inferior to the PCC peak from the levodopa challenge analysis.

\section{PET: Levodopa Response across All Subjects}

Responses to levodopa across both groups included significant regional increases in blood flow (experimentwise $p<0.0002$ ), with the largest cluster encompassing midbrain and pons and extending into temporal lobe and thalamus (see Table 2; uncorrected $p \ll 10^{-5} ; 73.5 \mathrm{ml}$ ). Regional CBF also increased significantly in three other clusters, including lateral orbital cortex, bilateral insula, and middle and superior frontal gyrus (see Table 2). In the opposite direction, there was a significant pattern of decreased $\mathrm{rCBF}$ after levodopa (experimentwise $p \ll 10^{-5}$ ), but there were no clusters with peaks in the brain for which corrected $p<0.05$. At the uncorrected threshold of $t>3.17$, levodopa decreased $\mathrm{rCBF}$ in two small intracerebral clusters, one in cerebellum (peak $t=3.54$ at $(18,-62,-20), 0.5 \mathrm{ml}$ ) and in medial motor cortex (BA4; peak $t=3.45$ at $(-2,-36,58), 0.3 \mathrm{ml})$.

\section{PET: Comparison of Response to Levodopa between Mood Fluctuators and Controls}

There was a significant difference between groups in the regional blood flow response to levodopa (mood $>$ nonmood, experimentwise $p=0.002$; $\operatorname{mood}<$ nonmood, experimentwise $p<10^{-5}$ ). One cluster of voxels centered in the brain met the predetermined criterion for significance after correction for multiple comparisons. This cluster was identified in the mood $>$ nonmood comparison (corrected $p<0.01$ ) and contained two peaks centered at $(-2,-26,54)$ and $(-6,-26,36)$ (see Table 3 and Figure 1, top row). The first peak in this region is centered in medial frontal gyrus near the central sulcus, and the second peak lies in PCC. Mean values from spherical VOIs centered on these peaks show that PD control patients have decreased rCBF after levodopa, while mood fluctuators do not (repeated measures ANOVA, $\mathrm{F}_{1,19}=5.086, p<0.04$; post hoc Scheffe tests indicate a decrease with levodopa in the motor fluctuator group at $p<0.06$ but $p>0.25$ for all other comparisons). Data from the PCC peak are summarized in Figure 2. Other voxel clusters exceeding $t=3.17$ are described in Table 3 and Figure 1 .

No intracerebral cluster in the mood $<$ nonmood comparison reached the specified significance criterion, but one cluster with corrected $p<0.08$ had peak $t=4.37$ at $(20,-22,-16)$ in the body of the hippocampus $(2.6 \mathrm{ml})$. The only other intracerebral voxel clusters surpassing

Table 2 Most Significant Regional Effects of Levodopa across All Subjects

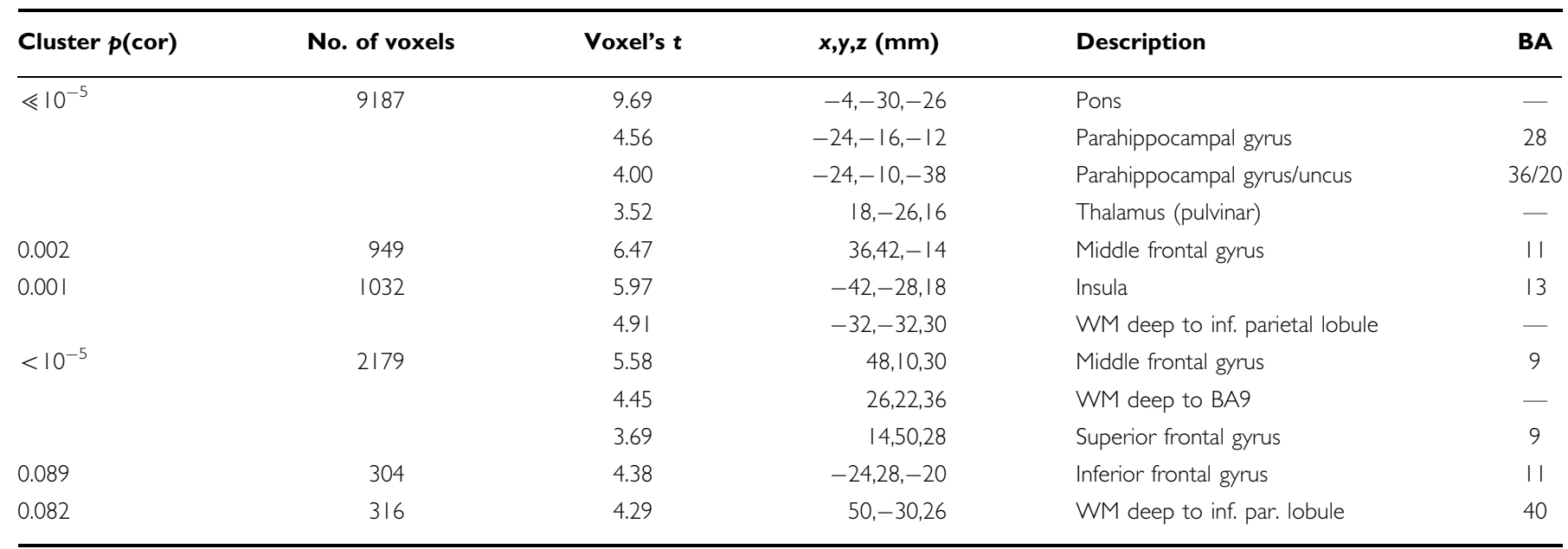

Most significant clusters of contiguous voxels with $t>3.17$ ( $100 \mathrm{df}$ ), and local maxima within each cluster separated by more than $8 \mathrm{~mm}$. See legend to Table 2 for abbreviations. 

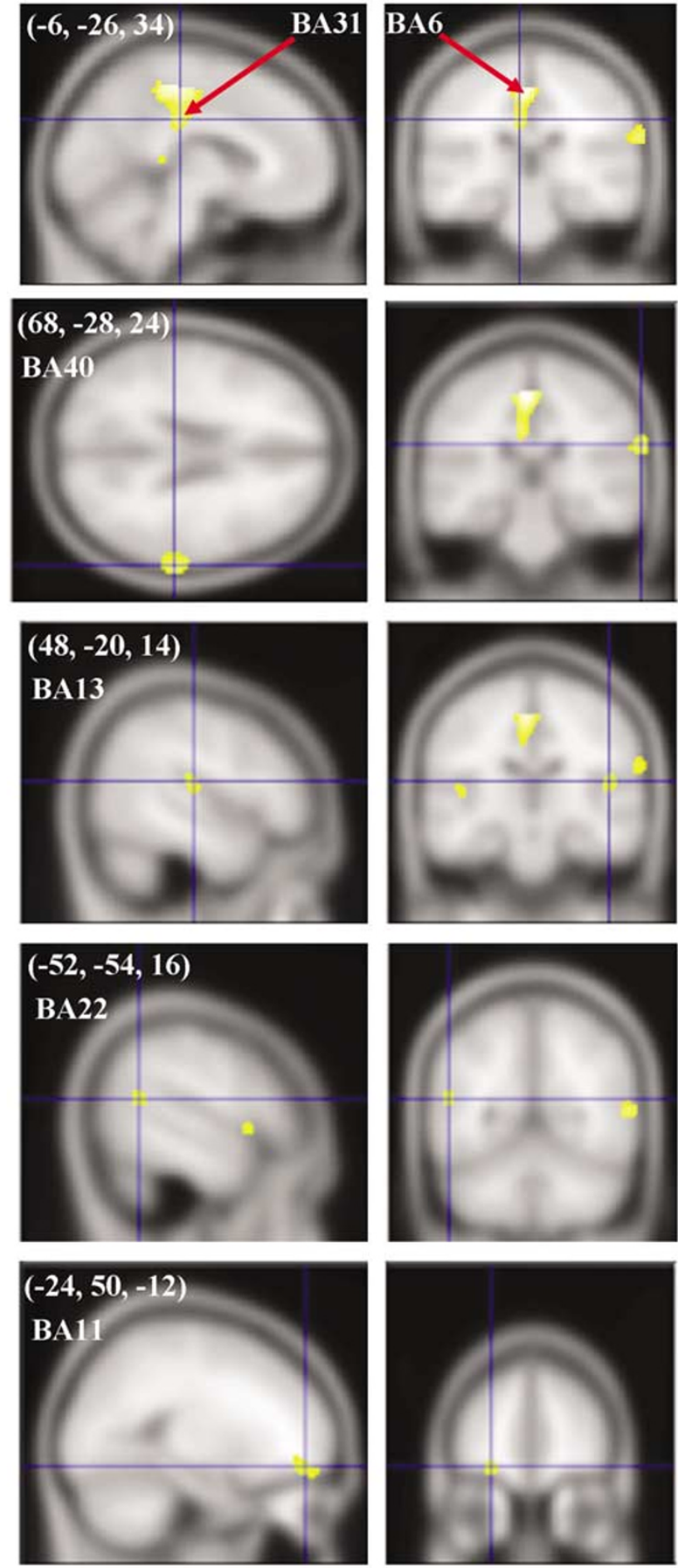

Figure I Top row: Mood fluctuators differed significantly from control patients with motor fluctuations only (Table 2). The t image is shown in color superimposed on an averaged structural MR image in grayscale. The crosshairs are at the statistical peak in PCC $(-6,-26,34)$. On coronal images, the right side of the brain is shown on the right side of the figure. Other rows: Additional regions of possible group difference in levodopa response (Table 2). From top to bottom: Inferior parietal lobule, crosshairs at $(68,-28,24)$, insula $(48,-20,14)$, superior temporal gyrus $(-52,-54,16)$, lateral orbital cortex $(-24,50,-12)$.

$t=3.17$ had peaks at $(28,4,-20)$ (uncus, BA28, peak $t=4.01$, $1.1 \mathrm{ml}),(-26,-22,18)$ (claustrum, peak $t=3.69,0.3 \mathrm{ml})$, and $(-24,-2,-40)$ (uncus, near BA20, peak $t=4.01,0.2 \mathrm{ml}$ ).

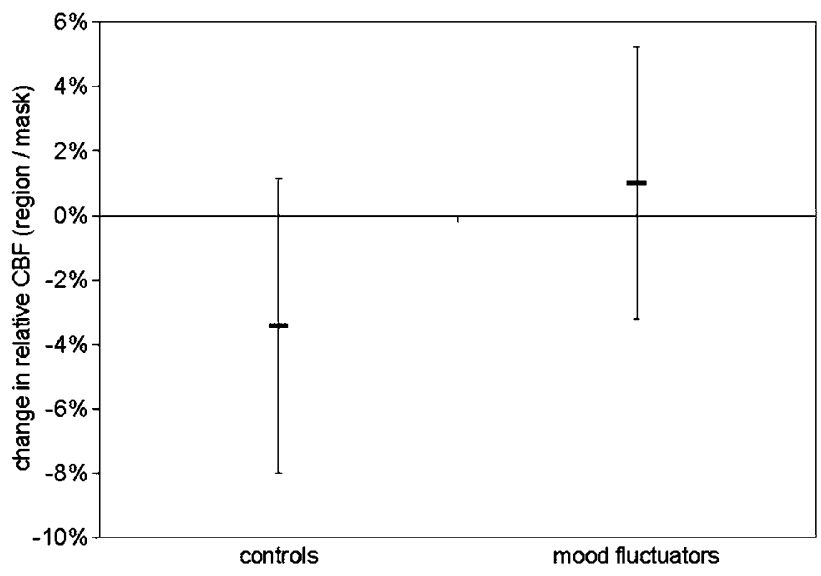

Figure 2 The figures show mean $+S D$ rCBF in an $8 \mathrm{~mm}$ spherical VOI centered at the PCC peak shown in Figure I, before and after levodopa, in mood fluctuators and in control patients with motor fluctuations only. Note that each $\mathrm{VOI}$ includes data from 35 surrounding voxels in addition to the voxel at the statistical peak.

\section{Clinical Observations}

There were no significant differences between groups on the baseline characteristics listed in Table $1(p>0.10)$, except that mood fluctuators were being treated with a higher total daily dose of levodopa or dopamine agonists $(p<0.05)$.

Clinical ratings of depression and anxiety, based on symptoms during the week prior to the scan, showed a modest overall severity of mood and anxiety, with the mean in the nondepressed range (see Table 4). This is consistent with the clinical description, since episodic, ultradian symptoms define the group of interest, rather than sustained symptoms. Ratings of parkinsonian severity in both groups diminished by roughly half following treatment (repeated measures ANOVA, drug effect $p<0.005 ; p>0.20$ for both the diagnosis effect and the interaction), and most subjects had peak-dose dyskinesias (Table 4).

One mood fluctuator patient was crying in the waiting room before the scan. Three mood fluctuators showed hypomanic behavior after levodopa, including euphoria, flirting or inappropriate sexual comments, silly or giddy behavior, joking, and talkativeness. Severity was mild, with Bech mania scores of $1.5,2$, and 4 . One patient showed severe wearing-off bradyphrenia, trailing off to mutism while answering a question, only to spontaneously finish the sentence $10 \mathrm{~min}$ later during levodopa infusion. One additional mood fluctuator patient said 'I feel like I took an upper.' One control subject felt mood had improved and another denied change in mood per se but said 'mentally, I feel better.'

Surprisingly, several mood fluctuator patients did not have marked sadness and anxiety during the baseline scans, and baseline mood ratings did not differ between patient groups (Table 4). Patients told us they felt emotionally better during the study baseline than during their usual off periods, and this was confirmed by their caregivers. Based on their comments and our observations, we speculate that the constant personal attention we provided during the study somewhat reduced the severity of their off-period anxiety and depression. To a small extent, the modest severity of baseline symptoms on the study day may also 
Table 3 Most Significant Regional Differences in Levodopa Response in the Mood Fluctuators > Motor Fluctuators Comparison

\begin{tabular}{lccll}
\hline Cluster p(cor) & No. of voxels & Voxel's & $\mathbf{x , y , z ~ ( m m ) ~}$ & Description \\
\hline 0.009 & 662 & 4.53 & $-2,-26,54$ & Medial frontal gyrus \\
& & 3.79 & $-6,-26,34$ & Posterior cingulate \\
0.513 & 75 & 3.68 & $60,-54,10$ & Superior temporal gyrus \\
0.163 & 221 & 3.68 & $68,-28,24$ & Inferior parietal lobule \\
0.733 & 30 & 3.49 & $-50,14,-2$ & Inferior frontal gyrus \\
0.607 & 54 & 3.47 & $48,-20,14$ & Insula \\
0.803 & 18 & 3.42 & $-4,-38,10$ & Splenium/posterior cingulated \\
0.647 & 46 & 3.40 & $-52,-54,16$ & WM deep to superior temporal gyrus \\
0.474 & 85 & 3.40 & $-24,50,-12$ & Middle frontal gyrus \\
0.797 & 19 & 3.35 & $-44,-20,10$ & WM deep to transverse temporal gyrus \\
\hline
\end{tabular}

Most significant clusters of contiguous voxels with $t>3.17$ (I00 df), and local maxima within each cluster separated by more than $8 \mathrm{~mm}$ (Figure I). $p$ (cor): $p$-value corrected for multiple comparisons; no. of voxels: number of contiguous voxels in each cluster; $x, y, z$ : Talairach atlas coordinates; BA: Brodmann area. Voxel volume $=8 \mathrm{~mm}^{3}$.

Table 4 Scan-Day Symptoms

\begin{tabular}{lcc}
\hline & Mood fluctuators & Controls \\
\hline Ham-D & $8.3 \pm 4.9$ & $5.0 \pm 4.6$ \\
Ham-A & $8.9 \pm 4.8$ & $5.8 \pm 2.6$ \\
& & \\
Mood VAS ratings during scans (mm) & $61 \pm 23$ & $58 \pm 14$ \\
Sad (0)-happy (I00), baseline & $86 \pm 12$ & $71 \pm 13$ \\
Sad (0)-happy (I00), levodopa & & \\
Modified UPDRS (maximum = 32) & $7.1 \pm 3.7$ & $11.8 \pm 9.3$ \\
Baseline & $4.1 \pm 1.7$ & $6.5 \pm 3.7$ \\
Levodopa & 6 & 10 \\
Number with dyskinesias after levodopa & & \\
\hline
\end{tabular}

reflect a selection bias away from the most severely affected patients: two mood fluctuation patients who came to the PET suite to participate were unable to do so, one due to marked off-period anxiety and the other due to severe offperiod neck flexor dystonia. Both patient groups had higher in-scanner mood scores on levodopa (ANOVA, significant effect of levodopa, $p<0.001$ ), but the increase was twice as great in the mood fluctuators (interaction of diagnosis and levodopa status, $p=0.12$; post hoc two-tailed $t$-test, $p=0.02$; see Table 4).

\section{Levodopa Plasma Concentrations}

Mean plasma concentrations increased from $132 \pm 177 \mathrm{ng} /$ $\mathrm{ml}$ at baseline to $1590 \pm 513 \mathrm{ng} / \mathrm{ml}$ after levodopa administration. There was no significant difference between groups in levodopa plasma concentrations either before or after drug.

\section{Subgroup Analyses}

We examined whether it was likely that factors other than the mood fluctuation diagnosis affected the most significant
Table 5 Mood Fluctuation Subtype and PCC Response to Levodopa

\begin{tabular}{lccc}
\hline Off depression & Off anxiety & On mania & PCC response (\%) \\
\hline$N$ & $Y$ & $N$ & -5.0 \\
$N$ & $N$ & $Y^{a}$ & -1.7 \\
$N$ & $N$ & $Y$ & -.5 \\
$Y$ & $Y$ & $N$ & -1.5 \\
$N$ & $Y$ & $Y$ & +2.4 \\
$N$ & $Y$ & $Y$ & +3.4 \\
$Y$ & $Y$ & $N$ & +3.7 \\
$Y$ & $N$ & $Y$ & +8.3 \\
\hline
\end{tabular}

Additional diagnoses were off-period apathy (I) and off-period bradyphrenia ( I).

aThis patient had on-period hypomania.

result in our primary PET analysis. First, some subjects in each group received levodopa by mouth rather than i.v. Ignoring these subjects, the mean PCC rCBF response was $-3.5 \%$ (controls) $v s+1.3 \%$ (mood fluctuators), similar to the means for all subjects at $-3.6 \%$ (controls) and $+0.8 \%$ (mood fluctuators). Thus the route of administration seems to have had little effect on the main result. Second, one subject in each group was scanned on the $953 \mathrm{~b}$ scanner. Ignoring those two subjects, the mean PCC rCBF response was $-3.9 \%$ (controls) and $1.3 \%$ (mood fluctuators), again suggesting no meaningful difference. Third, the mood fluctuation group included patients with various combinations of off-period depression, off-period anxiety, and onperiod mania or hypomania. The possible effect of mood fluctuation subtype on PCC rCBF response to levodopa is shown in Table 5; the numbers are too small and the pattern too irregular for definitive conclusions, but the most 'typical' response (ie the highest) for the mood fluctuator group is in the only subject with both off-period depression and on-period mania, while the most atypical (ie the most negative) response was in the only subject with neither.

Finally, some subjects in each group were taking an antidepressant (Table 1). Apparently antidepressants alone do not explain the group difference in PCC response to 
levodopa, since within the motor fluctuator control group the response was similar regardless of antidepressant exposure (antidepressant, $N=5,-3.8 \%$; none, $N=8$, $-3.4 \%)$. Mood fluctuators differed more, but neither subgroup approached the responses of the controls (antidepressant, $N=6,+1.4 \%$; none, $N=2,-0.9 \%$ ).

\section{DISCUSSION}

\section{Baseline Differences in Resting rCBF in Mood Fluctuators}

To our knowledge, no other anatomic or functional imaging studies have compared PD patients with and without levodopa-related mood fluctuations. Published comparisons of regional resting brain metabolism or rCBF between PD patients with and without (nonfluctuating) major depression have shown decreased activity of caudate nuclei and prefrontal cortex (Mayberg et al, 1990; Jagust et al, 1992; Mayberg, 1994; Ring et al, 1994). The decreased caudate activity likely represents a true decrease per unit volume rather than a partial volume effect (Lisanby et al, 1993, $\mathrm{p}$ 18). In a before- and after-treatment FDG PET study of depressed PD patients, an antidepressant response to fluoxetine was associated with a metabolic increase in dorsal anterior cingulate regional metabolism and a metabolic decrease in ventral anterior cingulate (Stefurak et al, 2001; Mayberg, 2003). None of these differences were detected in the mood fluctuators, in whom baseline rCBF differed only at a few voxels over $3 \mathrm{~cm}$ away.

\section{Regional CBF Response to Levodopa in the Whole Sample}

The responses to levodopa in the combined patient sample largely replicate those we previously observed in three separate samples of PD patients as well as in healthy controls (Hershey et al, 1998, 2003). The large brainstem response to levodopa or dopamine agonists has been reported in various species, and involves a diffuse midbrain area even when assessed at much higher image resolution using $\left[{ }^{14} \mathrm{C}\right] 2$-deoxyglucose and ex vivo film autoradiography (Trugman and Wooten, 1986; Grasby et al, 1993; Kapur et al, 1994; Hershey et al, 2000; Black et al, 2000). In the rodent studies, the response includes superior colliculus, midbrain reticular formation, and subthalamic nucleus. Other levodopa-responsive regions in Table 3 (eg parahippocampal gyrus, insula, and lateral orbital cortex) were not reported in our previous studies of levodopa activation, and may also mediate dopaminergic influences on mood or cognition. Together, these studies provide substantial information on the functional responses to levodopa in normal and parkinsonian humans.

Other groups have also reported levodopa activation imaging studies in $\mathrm{PD}$, as reviewed in part by Hershey et al (2003). An early PET study found no rCBF differences after levodopa in 10 motor fluctuators (Melamed et al, 1986). Feigin et al (2001) report an FDG PET levodopa activation study in seven PD patients. As in the present study, they found a statistically modest decrease in activity in cerebellum. Similar decreases occurred in putamen, thalamus, and primary motor cortex; these likely would not have been identified in our study due to differences in statistical threshold and axial field of view. Berding et al (2001) report a similar study in 11 PD subjects; regional metabolism decreased in orbital cortex (peak change was $12 \mathrm{~mm}$ from the peak in Table 2). Neither study detected regional increases, which may relate to sample size or differences in levodopa challenge.

\section{Regional CBF Response to Levodopa in Mood Fluctuators vs Motor Fluctuator Controls}

The primary PET analysis shows that the brain's regional response to levodopa is significantly different in PD patients with levodopa-dose-related emotional changes, compared to similar patients with fluctuations only in motor function. The rCBF response to levodopa detected group differences not evident in the group comparison of baseline resting $\mathrm{rCBF}$.

The most significant group difference in $\mathrm{rCBF}$ response to levodopa occurred in a contiguous medial cortical region containing a superior and an inferior peak. The superior peak (BA6) may reflect group differences in motor cortex innervation by dopamine-influenced neurons, and may be important to mood fluctuations or may represent imperfect group matching on motor features of PD (although the groups compared very closely on duration of illness, clinical ratings of parkinsonism, and prevalence of levodopainduced dyskinesias). The other peak is centered in PCC, which has previously been shown to be abnormally active in depression or anxiety. This region probably includes BA31 (Talairach and Tournoux, 1988) and retrosplenial cortex, which in primates extends this far anteriorly along the corpus callosum (Parvizi et al, 2003).

\section{Posterior Cingulate Cortex}

In a PET study of major depression, metabolism in this part of PCC (peaks at $(-8,-32,30)$ and $(6,-26,32)$ ) significantly increased in patients who responded to 6 weeks of fluoxetine treatment, but significantly decreased in nonresponders (Mayberg et al, 2000). Posterior cingulate metabolism had decreased in both groups after 1 week of fluoxetine treatment, before depression improved. In other words, activity of PCC was a state marker for remission of major depression (increase), and for nontherapeutic exposure to fluoxetine (decrease). Similar results were observed over a much shorter time scale in an rCBF study of induced sadness or anxiety in normal volunteers (Liotti et al, 2000). Decreased activity was observed during anxious and depressed states in PCC, with peak differences at $(6,-64,17)$ and $(3,-40,20)$, somewhat posterior and inferior to those seen here.

PCC activity is also linked to anxiety in different model conditions. Breathlessness and air hunger induced by inhalation of $8 \% \mathrm{CO}_{2}$ caused decreased PCC blood flow with peak change at $(0,-36,32)$ (Brannan et al, 2001), and there was an $\sim 5 \%$ decrease in PCC rCBF in volunteers who were anxious while awaiting a painful shock to the hand (did not reach statistical significance using conservative methods) (Simpson et al, 2001). In studies of post-traumatic stress disorder that provoked anxiety by presenting traumarelated pictures and sounds, activations or deactivations 
were found in PCC (Shin et al, 1997; Bremner et al, 1999a, b; Liberzon et al, 1999). As in our study, Bremner et al (1999b) found that posterior cingulate activation in patients was sometimes of opposite sign than in healthy controls.

From such studies, Liotti et al (2000) concluded, it is clear that the posterior cingulate plays a critical role in the regulation of both normal and pathologic negative emotions' (p 36). In fact, Maddock (1999) noted that after inferior prefrontal cortex, PCC (including retrosplenial cortex) was the brain region most consistently activated in 51 functional neuroimaging studies of emotion. The specific role PCC plays in emotion is not clear, but available data suggest that it may encode the emotional significance of stimuli, perhaps by mediating the comparison of present percepts to emotions associated with episodic (eg autobiographical) memory (Maddock, 1999).

The $\mathrm{rCBF}$ response in posterior cingulate may arise either from neurons intrinsic to PCC or from afferent projection axons terminating in PCC. Afferents to PCC include contralateral PCC; ipsilateral anterior cingulate cortex (dorsal and ventral), posterior parietal cortex, superior temporal sulcus (STS), parahippocampal gyrus, ventral claustrum, and both orbital and dorsal prefrontal cortex; certain thalamic nuclei (pulvinar, lateral dorsal, anterior dorsal, anterior ventral); raphe nuclei and locus ceruleus; and the rostral medial anterior portion of caudate nucleus (Vogt et al, 1979, 2003; Baleydier and Mauguiere, 1980; Van Hoesen et al, 1993; Parvizi et al, 2003). These regions may help explain how PCC is modulated by dopamine or mood.

Dopaminergic modulation of PCC metabolism and blood flow may arise directly from the caudate, which receives a heavy dopaminergic innervation. However, dopamine could influence PCC indirectly via other brain regions. For instance, in a primate model, the most significant effects on rCBF after administration of a dopamine agonist occurred in STS after a D1 agonist and in orbital prefrontal cortex after a D3-preferring agonist (Black et al, 1997, 2002b). Both regions project to PCC. In any case, levodopa and several dopamine agonists clearly affect PCC rCBF (Friston et al, 1992; Black et al, 2002a, b; Hershey et al, 2000).

Afferents to PCC may also contribute to the relationship of emotion with PCC rCBF. For example, metabolism in both rostral and ventral portions of anterior cingulate cortex is abnormal in major depression (Drevets, 2001; Mayberg, 1997). Patients with familial pure major depression show decreased rCBF, metabolism, volume, and glial cell number in subgenual anterior cingulate cortex (Drevets et al, 1997; Öngür et al, 1998). Thus an altered PCC response to dopamine in patients with mood fluctuations may reflect abnormal dopaminergic modulation of caudate, anterior cingulate, or prefrontal cortex. One possible mechanism could be differential loss of dopamine innervation to these nuclei; no data directly address this possibility, but Torack and Morris (1988) did find greater cell loss in ventral tegmental area in PD patients with an antemortem diagnosis of depression.

\section{PCC: A Hypothesis}

The motor fluctuator controls responded to levodopa with a decrease in PCC rCBF, an apparently normal response replicated by D2-like agonists (Hershey et al 2000; Black et al 2002a, b). Decreased PCC activity is often associated with anxiety or sadness (Mayberg, 2003), but must not be sufficient to produce these emotions since levodopa and D2-like agonists do not usually cause anxiety or sadness. We speculate that dopaminergic pathways that affect PCC activity may mitigate extremes of mood. The mood fluctuators' loss of the PCC response to levodopa may thus be related to their clinical experience of emotional extremes. The valence of the dopamine-related mood changes may be determined by activity in other, anatomically connected, areas of the brain such as anterior cingulate or orbital cortex.

\section{Other Group Differences in rCBF Responses to Levodopa}

Several other regions showed a more positive response to levodopa in mood fluctuators. These included regions near STS, the inferior parietal lobule, the insula, and orbital frontal cortex (Table 2 and Figure 1). Lateral orbital cortex (BA11) is strongly implicated in regulation of mood and impulsivity, receives striatal afferents, and is influenced by dopamine, suggesting that this region may be relevant to the mood and anxiety fluctuations that differentiate our two groups of patients (Öngür and Price, 2000; Black et al, 2002b). A PET study of major depression identified rCBF in posterior inferior parietal lobule as correlated with anxiety (Grasby et al, 1993). In several studies, decreased metabolic activity in inferior parietal cortex (BA40) corresponds highly with state sadness or with an anxiety disorder, but the peak in Table 2 is at least $26 \mathrm{~mm}$ from these regions (Mayberg et al, 1999; Bremner et al, 1999a,b). Levodopa does decrease inferior parietal blood flow in patients and normal controls (Hershey et al, 2003). Several studies of sadness or anxiety have detected abnormal activity of insula, primarily but not exclusively anterior insula (Malizia, 1999; Mayberg et al, 1999). There is no obvious relationship of STS or surrounding cortex to mood regulation, but STS rCBF is affected by dopamine agonists (Black et al, 2000).

A cluster of voxels in hippocampus and parahippocampal gyrus reacted in the opposite direction (more negative response to levodopa in mood fluctuators, $p<0.08$ ). The potential role of the hippocampus in idiopathic major depression has been reviewed recently (Sheline et al, 2002; Mayberg, 2003). Chronicity of major depression is associated with decreased hippocampal volume (Sheline et al, 1996). Furthermore, in serotonergic treatment of major depression, either with or without PD, hippocampal activity decreases with treatment response but increases with treatment failure (Mayberg, 2003). This pattern is not seen with response to cognitive therapy or placebo, however. Conceivably, the greater decrease in hippocampal activity with levodopa in mood fluctuators corresponds to the greater improvement in mood in these subjects.

\section{Pharmacology}

The relationship of dopamine to (nonfluctuating) depression in PD is unclear (Bunney et al, 1969; Jouvent et al, 1983; Mayeux et al, 1986; Torack and Morris, 1988; 
Cummings, 1992; Kostic et al, 1996; Black and Pandya, in press). By contrast, levodopa-related mood fluctuations in PD have a strongly face valid relationship to brain dopamine concentrations. Dopaminergic effects on mood are well documented and have been reviewed elsewhere (Drevets et al, 2001; Klimek et al, 2002; Racette et al, 2002). However, there is little direct evidence as to what receptor subtype(s) may mediate dopamine's modulation of emotional symptoms or $\mathrm{rCBF}$ in these mood fluctuation patients.

Recent pharmacologic activation PET studies in a primate model may shed light on this question. The activation of PCC rCBF by levodopa is replicated by D2-like dopamine agonists, but not by a D1 agonist (Black et al, 2000, 2002a, b). Similarly, lateral orbitofrontal cortex was strongly activated in normal baboons by the D3-preferring agonist pramipexole (Black et al, 2002b), and superior temporal gyrus is strongly activated by a D1 agonist (Black et al, 2000). Further study will be required to confirm whether PD patients with mood fluctuations have more pronounced mood responses to D2-like than to D1-like dopamine agonists, or whether the imaging findings in this levodopa activation study can be replicated with specific agonists.

\section{Clinical Results, Limitations, and Future Directions}

The two study groups were defined by a clinical history of mood fluctuations. In the PET scanner, the two groups had only modest differences in mood ratings. In interpreting the imaging results, this observation reduces the possible confound of state-related group differences during the scan session. A similar dissociation between usual clinical response outside the scanner and clinical observations in the experimental setting benefited our prior levodopa challenge PET study of drug-induced dyskinesias (Hershey et al, 1998). However, state-related changes in mood may be examined if larger in-scanner fluctuations of mood are observed in future patients.

The small number of subjects makes the study vulnerable to Type II errors. For instance, previous studies of resting regional brain metabolism in $\mathrm{PD}$ detected significant abnormalities in patients with major depression (Mayberg et al, 1990). Mood fluctuators were taking more levodopa and dopamine agonists, but this likely reflects efforts to treat off-period psychiatric symptoms, given the comparable off-period motor signs and duration of illness (Table 1). Additional limitations of this study include the potential for unidentified clinical differences between groups, and the heterogeneity in clinical and study procedures addressed in Results. Also, regional blood flow is an indirect measure of regional metabolism and neuronal function, and its interpretation depends on the tight coupling between $\mathrm{rCBF}$ and regional metabolism. This coupling is preserved even in the presence of non-ergot dopamine agonists (McCulloch et al, 1982), and is likely even more stable in our experiment, since with levodopa/carbidopa, dopamine production outside the brain is blocked and levodopa has no net effect on whole-brain blood flow (Hershey et al, 1998, 2000, 2003).

Our results demonstrate the utility of the pharmacologic activation approach in studying neuropsychiatric illness: although PCC has known dopamine-influenced afferents and known association with emotional regulation, it has not previously been considered in discussions of levodoparelated mood fluctuations in PD. Also, in the absence of pharmacologic stimulation, no baseline difference in PCC rCBF was identified. Future clinical, neuroimaging, and pathological studies may clarify the pathophysiology and pharmacology of PCC with respect to levodopa-mediated effects on mood.

\section{ACKNOWLEDGEMENTS}

The study was supported by Jonathan M Koller, Lennis Lich (Washington University), and Dr Kathryn Vehe (BarnesJewish Hospital). Patient self-ratings software was designed by Dr Robert J Feiwell. Patient referral was by Drs Jonathan W Mink (now at University of Rochester Medical Center), Brad A Racette, and Fredy J Revilla (now at University of Cincinnati College of Medicine). This work was presented in part at the Mental and Behavioral Dysfunction in Movement Disorders International Symposium, Montréal, Canada, 1013 October 2001, at the Society for Neuroscience annual meeting, San Diego, California, 14 November 2001, and at the American College of Neuropsychopharmacology annual meeting, 10 December 2001. Funding was provided by NINDS (NS01898), the American Parkinson Disease Association (APDA) Advanced Research Center at Washington University and the Greater St Louis chapter of the APDA, the Charles A Dana Foundation, and the McDonnell Center for Higher Brain Function. KJB was supported by a Young Investigator Award from the National Alliance for Research on Schizophrenia and Depression (NARSAD).

\section{REFERENCES}

Baleydier C, Mauguiere F (1980). The duality of the cingulate gyrus in monkey. Neuroanatomical study and functional hypothesis. Brain 103: 525-554.

Baruzzi A, Contin M, Albani F, Riva R (1986). Simple and rapid micromethod for the determination of levodopa and 3-Omethyldopa in human plasma by high-performance liquid chromotography with coulometric detection. J Chromatogr B 375: 165-169.

Berding G, Odin P, Brooks DJ, Nikkhah G, Matthies C, Peschel T et al (2001). Resting regional cerebral glucose metabolism in advanced Parkinson's disease studied in the off and on conditions with [(18)F]FDG-PET. Mov Disord 16: 1014-1022.

Black KJ, Carl JL, Hartlein JM, Warren SL, Hershey T, Perlmutter JS (2003). Rapid intravenous loading of levodopa for human research: clinical results. J Neurosci Methods 127: 19-29.

Black KJ, Gado MH, Perlmutter JS (1997). PET measurement of dopamine D2 receptor-mediated changes in striatopallidal function. J Neurosci 17: 3168-3177.

Black KJ, Hershey T, Gado MH, Perlmutter JS (2000). Dopamine $\mathrm{D}_{1}$ agonist activates temporal lobe structures in primates. $J$ Neurophysiol 84: 549-557.

Black KJ, Hershey T, Koller JM, Carl JL, Perlmutter JS (2002a). Mapping and quantification of dopamine D2 receptor activation. J Neuropsychiatr Clin Neurosci 14: 118-119 (abstract).

Black KJ, Hershey T, Koller JM, Videen TO, Mintun MA, Price JL et al (2002b). A possible substrate for dopamine-related changes in mood and behavior: prefrontal and limbic effects of a D3-preferring dopamine agonist. Proc Natl Acad Sci USA 99: 17113-17118. 
Black KJ, Pandya A. Depression in Parkinson disease. In: Gilliam F, Sheline YI (eds). Depression and Brain Dysfunction. Parthenon Publishing: Oxon, UK (in press).

Brannan S, Liotti M, Egan G, Shade R, Madden L, Robillard R et al (2001). Neuroimaging of cerebral activations and deactivations associated with hypercapnia and hunger for air. Proc Natl Acad Sci USA 98: 2029-2034.

Bremner JD, Narayan M, Staib LH, Southwick SM, McGlashan T, Charney DS (1999a). Neural correlates of memories of childhood sexual abuse in women with and without posttraumatic stress disorder. Am J Psychiatry 156: 1787-1795.

Bremner JD, Staib LH, Kaloupek D, Southwick SM, Soufer R, Charney DS (1999b). Neural correlates of exposure to traumatic pictures and sound in Vietnam combat veterans with and without posttraumatic stress disorder: a positron emission tomography study. Biol Psychiatry 45: 806-816.

Bunney WE, Janowsky DS, Goodwin FK, Davis JM, Brodie HKH, Murphy DL et al (1969). Effect of L-dopa on depression. Lancet 1: 885-886.

Cantello R, Gilli M, Riccio A, Bergamasco B (1986). Mood changes associated with 'end-of-dose deterioration' in Parkinson's disease: a controlled study. J Neurol Neurosurg Psychiatry 49: 1182-1190.

Carl JL, Perlmutter JS (1998). A new method to measure L-DOPA \& metabolites in plasma. Soc Neurosci Abstr 24: 352 (abstract).

Carter JH, Lyons KS, Stewart BJ, Archibald P (2002). Do the clinical features of Parkinson's disease explain spouse caregiver strain? Neurology 58: A468 (abstract).

Cotzias GC, van Woert HH, Schiffer LM (1967). Aromatic amino acids and modifications of parkinsonism. $N$ Engl J Med 276: 374-379.

Cummings JL (1992). Depression and Parkinson's disease: a review. Am J Psychiatry 149: 443-454.

Damásio AR, Lobo-Antunes J, Macedo C (1971). Psychiatric aspects in Parkinsonism treated with L-dopa. J Neurol Neurosurg Psychiatry 34: 502-507.

Drevets WC (2001). Neuroimaging and neuropathological studies of depression: implications for the cognitive-emotional features of mood disorders. Curr Opin Neurobiol 11: 240-249.

Drevets WC, Gautier C, Price JC, Kupfer DJ, Kinahan PE, Grace AA et al (2001). Amphetamine-induced dopamine release in human ventral striatum correlates with euphoria. Biol Psychiatry 49: $81-96$.

Drevets WC, Price JL, Simpson Jr JR, Todd RD, Reich T, Vannier $M$ et al (1997). Subgenual prefrontal cortex abnormalities in mood disorders. Nature 386: 824-827.

Duvoisin RC (1974). Variations in the on-off phenomenon. $A d v$ Neurol 5: 339-340.

Feigin A, Fukuda M, Dhawan V, Przedborski S, Jackson-Lewis V, Mentis MJ et al (2001). Metabolic correlates of levodopa response in Parkinson's disease. Neurology 57: 2083-2088.

Folstein MF, Luria R (1973). Reliabiliy, validity, and clinical application of the visual analogue mood scale. Psychol Med 3: 479-486.

Friedenberg DL, Cummings JL (1989). Parkinson's disease, depression, and the on-off phenomenon. Psychosomatics 30: 94-99.

Friston KJ, Ashburner J, Frith CD, Poline J-B, Heather JD, Frackowiak RSJ (1995). Spatial registration and normalization of images. Hum Brain Mapp 2: 165-189.

Friston KJ, Grasby PM, Bench CJ, Frith CD, Cowen PJ, Liddle PF et al (1992). Measuring the neuromodulatory effects of drugs in man with positron emission tomography. Neurosci Lett 141: 106-110.

Goodwin FK (1990). Biochemical and pharmacological studies. In: Goodwin FK, Jamison KR (eds). Manic-Depressive Illness. Oxford University Press: New York. pp 416-502.
Grasby PM, Friston KJ, Bench CJ, Cowen PJ, Frith CD, Liddle PF et al (1993). The effect of the dopamine agonist, apomorphine, on regional cerebral blood flow in normal volunteers. Psychol Med 23: 605-612.

Hardie RJ, Lees AJ, Stern GM (1984). On-off fluctuations in Parkinson's disease: a clinical and neuropharmacological study. Brain 107: 487-506.

Herscovitch P, Markham J, Raichle M (1983). Brain blood flow measured with intravenous $\mathrm{H}_{2}^{15}$ O.I. Theory and error analysis. J Nucl Med 24: 782-789.

Hershey T, Black KJ, Carl JL, McGee-Minnich LA, Snyder AZ, Perlmutter JS (2003). Chronic treatment and disease severity alter brain responses to levodopa in PD. J Neurol Neurosurg Psychiatry 74: 844-851.

Hershey T, Black KJ, Carl JL, Perlmutter JS (2000). Dopa-induced blood flow responses in non-human primates. Exp Neurol 166: 342-349.

Hershey T, Black KJ, Stambuk MK, Carl JL, McGee-Minnich LA, Perlmutter JS (1998). Altered thalamic response to levodopa in Parkinson's patients with dopa-induced dyskinesias. Proc Natl Acad Sci USA 95: 12016-12021.

Hobson DE, Lang AE, Martin WR, Razmy A, Rivest J, Fleming J (2002). Excessive daytime sleepiness and sudden-onset sleep in Parkinson disease: a survey by the Canadian Movement Disorders Group. J Am Med Assoc 287: 455-463.

Hornykiewicz O (1963). Die Topische Lokalisation und das Verhalten von Noradrenalin und Dopamin in der Substantia Nigra des normalen und Parkinsonkranken Menschen. Wien Klin Wochenschr 75: 309-312.

Hudziak JJ, Helzer JE, Wetzel MW, Kessel KB, McGee B, Janca A et al (1993). The use of the DSM-III-R Checklist for initial diagnostic assessments. Compr Psychiatry 34: 375-383.

Jagust WJ, Reed BR, Martin EM, Eberling JL, Nelson-Abbott RA (1992). Cognitive function and regional cerebral blood flow in Parkinson's disease. Brain 115: 521-537.

Jouvent R, Abensour P, Bonnet AM, Widlocher D, Agid Y, Lhermitte F (1983). Antiparkinsonian and antidepressant effects of high doses of bromocriptine. J Affect Disord 5: 141-145.

Kapur S, Meyer J, Wilson AA, Houle S, Brown GM (1994). Activation of specific cortical regions by apomorphine: an ${ }^{15} \mathrm{OH}_{2} \mathrm{O}$ PET study in humans. Neurosci Lett 176: 21-24.

Keshavan MS, David AS, Narayanen HS, Satish P (1986). 'On-off' phenomena and manic-depressive mood shifts: case report. $J$ Clin Psychiatry 47: 93-94.

Klimek V, Schenck J, Han H, Stockmeier C, Ordway G (2002). Dopaminergic abnormalities in amygdaloid nuclei in major depression: a postmortem study. Biol Psychiatry 52: 740-748.

Kostic VS, Lecic D, Doder M, Marinkovic J, Filipovic S (1996). Prolactin and cortisol responses to fenfluramine in Parkinson's disease. Biol Psychiatry 40: 769-775.

Lees AJ (1989). The on-off phenomenon. J Neurol Neurosurg Psychiatry 52(Suppl): 29-37.

Liberzon I, Taylor SF, Amdur R, Jung TD, Chamberlain KR, Minoshima $S$ et al (1999). Brain activation in PTSD in response to trauma-related stimuli. Biol Psychiatry 45: 817-826.

Liotti M, Mayberg HS, Brannan SK, McGinnis S, Jerabek P, Fox PT (2000). Differential limbic-cortical correlates of sadness and anxiety in healthy subjects: implications for affective disorders. Biol Psychiatry 48: 30-42.

Lisanby SH, McDonald WM, Massey EW, Doraiswamy PM, Rozear M, Boyko OB et al (1993). Diminished subcortical nuclei volumes in Parkinson's disease by MR imaging. J Neural Transm Suppl 40: 13-21.

Maddock RJ (1999). The retrosplenial cortex and emotion: new insights from functional neuroimaging of the human brain. Trends Neurosci 22: 310-316.

Malizia AL (1999). What do brain imaging studies tell us about anxiety disorders? J Psychopharmacol 13: 372-378. 
Maricle RA, Nutt JG, Carter JH (1995a). Mood and anxiety fluctuation in Parkinson's disease associated with levodopa infusion: preliminary findings. Mov Disord 10: 329-332.

Maricle RA, Nutt JG, Valentine RJ, Carter JH (1995b). Doseresponse relationship of levodopa with mood and anxiety in fluctuating Parkinson's disease: a double-blind, placebo-controlled study. Neurology 45: 1757-1760.

Maricle RA, Valentine RJ, Carter J, Nutt JG (1998). Mood response to levodopa infusion in early Parkinson's disease. Neurology 50: $1890-1892$.

Mayberg HS (1994). Frontal lobe dysfunction in secondary depression. J Neuropsychiatr Clin Neurosci 6: 428-442.

Mayberg HS (1997). Limbic-cortical dysregulation: a proposed model of depression. J Neuropsychiatr Clin Neurosci 9: 471-481.

Mayberg HS (2003). Modulating dysfunctional limbic-cortical circuits in depression: towards development of brain-based algorithms for diagnosis and optimised treatment. Br Med Bull 65: 193-207.

Mayberg HS, Brannan SK, Tekell JL, Silva JA, Mahurin RK, McGinnis S et al (2000). Regional metabolic effects of fluoxetine in major depression: serial changes and relationship to clinical response. Biol Psychiatry 48: 830-843.

Mayberg HS, Liotti M, Brannan SK, McGinnis S, Mahurin RK, Jerabek PA et al (1999). Reciprocal limbic-cortical function and negative mood: converging PET findings in depression and normal sadness. Am J Psychiatry 156: 675-682.

Mayberg HS, Starkstein SE, Sadzot B, Preziosi T, Andrezejewski PL, Dannals RF et al (1990). Selective hypometabolism in the inferior frontal lobe in depressed patients with Parkinson's disease. Ann Neurol 28: 57-65.

Mayeux R, Stern Y, Williams JB, Cote L, Frantz A, Dyrenfurth I (1986). Clinical and biochemical features of depression in Parkinson's disease. Am J Psychiatry 143: 756-759.

Mazziotta JC, Toga AW, Evans A, Fox P, Lancaster J (1995). A probabilistic atlas of the human brain: theory and rationale for its development. The International Consortium for Brain Mapping (ICBM). Neuroimage 2: 89-101.

McCulloch J, Kelly PA, Ford I (1982). Effect of apomorphine on the relationship between local cerebral glucose utilization and local cerebral blood flow (with an appendix on its statistical analysis). J Cereb Blood Flow Metab 2: 487-499.

Melamed E, Globus M, Mildworf B (1986). Regional cerebral blood flow in patients with Parkinson's disease under chronic levodopa therapy: measurements during 'on' and 'off' response fluctuations. J Neurol Neurosurg Psychiatry 49: 1301-1304.

Menza MA, Sage J, Marshall E, Cody R, Duvoisin R (1990). Mood changes and 'on-off phenomena in Parkinson's disease. Mov Disord 5: 148-151.

Nissenbaum H, Quinn NP, Brown RG, Toone B, Gotham A-M, Marsden CD (1987). Mood swings associated with the 'on-off' phenomenon in Parkinson's disease. Psychol Med 17: 899-904.

Öngür D, Drevets WC, Price JL (1998). Glial reduction in the subgenual prefrontal cortex in mood disorders. Proc Natl Acad Sci USA 95: 13290-13295.

Öngür D, Price JL (2000). The organization of networks within the orbital and medial prefrontal cortex of rats, monkeys and humans. Cereb Cortex 10: 206-219.

Parvizi J, Van Hoesen GW, Buckwalter JV, Vianna E (2003). The neural connectivity of the retrosplenial cingulate cortex. Presented at the 14th Annual Meeting, American Neuropsychiatric Association, Honolulu, HI, 2 February 2003.

Racette BA, Hartlein JM, Hershey T, Mink JW, Perlmutter JS, Black KJ (2002). Levodopa-related mood fluctuations in Parkinson's disease: clinical features and comorbidity. J Neuropsychiatr Clin Neurosci 14: 438-442.

Raichle M, Martin W, Herscovitch P, Mintun M, Markham J (1983). Brain blood flow measured with intravenous $\mathrm{H}_{2}^{15} \mathrm{O}$. II. Implementation and validation. J Nucl Med 24: 790-798.
Richard IH, Justus AW, Kurlan R (2001). Relationship between mood and motor fluctuations in Parkinson's disease. $J$ Neuropsychiatry Clin Neurosci 13: 35-41.

Riley DE, Lang AE (1993). The spectrum of levodopa-related fluctuations in Parkinson's disease. Neurology 43: 1459-1464.

Ring HA, Bench CJ, Trimble MR, Brooks DJ, Frackowiak RSJ, Dolan RJ (1994). Depression in Parkinson's disease: a positron emission study. Br J Psychiatry 165: 333-339.

Sheline YI, Mittler BL, Mintun MA (2002). The hippocampus and depression. Eur Psychiatry 17(Suppl 3): 300-305.

Sheline YI, Wang PW, Gado MH, Csernansky JG, Vannier MW (1996). Hippocampal atrophy in recurrent major depression. Proc Natl Acad Sci USA 93: 3908-3913.

Shin LM, Kosslyn SM, McNally RJ, Alpert NM, Thompson WL, Rauch SL et al (1997). Visual imagery and perception in posttraumatic stress disorder. A positron emission tomographic investigation. Arch Gen Psychiatry 54: 233-241.

Siemers ER, Shekhar A, Quaid K, Dickson H (1993). Anxiety and motor performance in Parkinson's disease. Mov Disord 8: 1-6.

Simpson Jr JR, Drevets WC, Snyder AZ, Gusnard DA, Raichle ME (2001). Emotion-induced changes in human medial prefrontal cortex: II. during anticipatory anxiety. Proc Natl Acad Sci USA 98: 688-693.

Stefurak TL, New P, Mahurin RK, Soloman D, Brannan D, Mayberg $\mathrm{H}$ (2001). Response specific regional metabolic changes with fluoxetine treatment in depressed Parkinson's patients. Mov Disord 16(Suppl 1): S39 (abstract).

Talairach J, Tournoux P (1988). Co-planar Stereotaxic Atlas of the Human Brain. Theime Verlag: New York.

Torack RM, Morris JC (1988). The association of ventral tegmental area histopathology with adult dementia. Arch Neurol 45: 497-501.

Trugman JM, Wooten GF (1986). The effects of L-DOPA on regional cerebral glucose utilization in rats with unilateral lesions of the substantia nigra. Brain Res 379: 264-274.

Van Hoesen GW, Morecraft RJ, Vogt BA (1993). Connections of the monkey cingulate cortex. In: Vogt BA, Gabriel M (eds). Neurobiology of Cingulate Cortex and Limbic Thalamus: A Comprehensive Handbook. Birkhäuser: Boston. pp 249-284.

Vázquez A, Jiménez-Jiménez FJ, Garcia-Ruiz P, Garcia-Urra D (1993). 'Panic attacks' in Parkinson's disease. A long-term complication of levodopa therapy. Acta Neurol Scand 87: 14-18.

Videen TO, Perlmutter JS, Herscovitch P, Raichle ME (1987). Brain blood volume, flow and oxygen utilization measured with O-15 radiotracers and positron emission tomography: revised metabolic computations. J Cereb Blood Flow Metab 7: 513-516.

Vogt BA, Hof PR, Vogt LJ (2003). Cingulate gyrus. In: Paxinos G, Mai JK (eds). The Human Nervous System, 2nd edn. Academic Press: San Diego. pp 915-949.

Vogt BA, Rosene DL, Pandya DN (1979). Thalamic and cortical afferents differentiate anterior from posterior cingulate cortex in the monkey. Science 204: 205-207.

Witjas T, Kaphan E, Azulay JP, Blin O, Ceccaldi M, Pouget J et al (2002). Nonmotor fluctuations in Parkinson's disease: frequent and disabling. Neurology 59: 408-413.

\section{APPENDIX}

\section{Criteria Used to Diagnose 'Clinically Significant Dopa-Related Mood Fluctuations'}

a. Marked anxiety, sadness, or mania, nearly always occurring at a predictable time relative to doses of dopamimetic medication.

b. Diagnosis follows 
1. corroboration of history by spouse or other informant, and

2. thorough neurological and psychiatric examination by a clinician experienced in evaluating mood symptoms in PD patients.

c. The symptoms cause clinically significant distress, or impairment in social, occupational, or other important areas of functioning.

d. The symptoms are not better accounted for by another syndrome, including major depression (ie while experiencing above symptoms, patient must have normal mood and interests most of the time for at least a month), pathological crying, or pure apathy; and are not more parsimoniously attributable to PD without depression (eg facial hypomimia, isolated fatigue, internal tremor' without other evidence of anxiety, or akathisia or tremor that the patient misidentifies as 'anxiety').

\section{A Screening Interview in a PD Patient Diagnosed with Clinically Significant Mood Fluctuations (Summary, Based on Contemporaneous Written Notes)}

First, the examiner established that the effect of each dose of levodopa often wore off before the next dose was due, despite successive changes in the dosage of levodopa/ carbidopa, switch to the sustained-release form, and addition of ropinirole and later tolcapone. Then, the examiner asked, 'What symptoms do you notice when your medicine wears off?' The patient replied, 'I have some stiffness, [pause] but what markedly changes is my mental attitude. I get depressed feeling and incapable of doing hardly anything.' On follow-up questions, he described feeling at those moments sad, blue, tearful, tense, and worried, with a 'negative attitude,' low energy, and poor concentration. At those times, 'I question whether life is worth living.' He was able occasionally to nap at these times. After taking his next dose of medication 'it kicks in about 30 min later and I feel good again.' A semistructured psychiatric interview (Hudziak et al, 1993) revealed no additional psychiatric symptoms except as follows. He twice had developed transient hallucinations in late life, once after surgery and once after addition of an unknown antiparkinsonian medication. He had a fear of heights starting in his 40s without significant distress or impairment. He had had no significant depressive symptoms until 10 years after the diagnosis of PD. At 3 years prior to study participation, after the death of his wife, he developed frequent sadness and initial or middle insomnia but (except when 'off') had normal appetite, normal concentration, no excessive guilt, no serious thoughts of suicide, and generally intact interests. He had never met research criteria for major depression. 